\title{
Upper-ocean currents around Taiwan
}

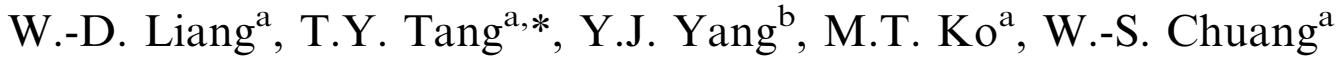 \\ a Institute of Oceanography, National Taiwan University, Taipei, Taiwan, Republic of China \\ ${ }^{\mathrm{b}}$ Department of Marine Science, Chinese Naval Academy, Kaohsiung, Taiwan, Republic of China
}

Accepted 12 October 2002

\begin{abstract}
Current velocity, measured by Shipboard Acoustic Doppler Current Profiler (Sb-ADCP) during 1991-2000, was used to study the upper-ocean $(<300 \mathrm{~m})$ currents around Taiwan. The collected data were debugged, calibrated, grid, and averaged to compose a three-dimensional current-velocity distribution. The validity of the composite current velocity was supported by 12 sets of moored current-velocity time series. Qualitative agreement was obtained. The moored time series also indicated that the seasonal variation of current around Taiwan was generally weak except for the shallowwater regimes.

The composite and moored currents revealed a branch of the Kuroshio that intruded steadily and persistently into the South China Sea. Part of the intruded Kuroshio flowed out of the South China Sea through the northern Luzon Strait and re-united with the main stream Kuroshio. The Kuroshio had two velocity maximum cores southeast of Taiwan, but gradually combined into one as the Kuroshio flowed north. The Kuroshio was deflected by the I-Lan Ridge east of Taiwan and the zonal-running shelf break northeast of Taiwan. At the shelf break, the Kuroshio split, with one branch intruding onto the shelf.

West of the Luzon Strait, the Kuroshio intruded into the South China Sea. Some water flowed northward into the Taiwan Strait and re-joined the Kuroshio. Currents in the Taiwan Strait flowed primarily in a northward direction, except for the southward current near the coast of Mainland China. North of the Taiwan Strait, a branch of the northward flow followed the northern coast of Taiwan to join the Kuroshio.

The composite current varied consistently from season to season. There was generally poor correlation between currents and local winds, especially in the deep-water regime. Remote forces were important in the currents around Taiwan.

(C) 2003 Elsevier Science Ltd. All rights reserved.
\end{abstract}

\section{Introduction}

Taiwan is an island located in the tropical to sub-tropical western Pacific (Fig. 1). East of Taiwan, where the shelf is narrow and the water is deep, lie Green Island, Yonaguni Island and the

\footnotetext{
*Corresponding author.

E-mail address: tyt@ ccms.ntu.edu.tw (T.Y. Tang).
}

islands of Lan-Yu. The I-Lan Ridge connects Yonaguni Island to Taiwan. Northeast of Taiwan, the shelf break extends northeastward, and turns abruptly toward the zonal direction around $26^{\circ} \mathrm{N}$. The North Mien-Hwa Canyon, which stretches across the shelf break around the turning point, connects the shelf of the East China Sea with the deep ocean basin. The shelf north of Taiwan is broad. The Taiwan Strait between Taiwan and 


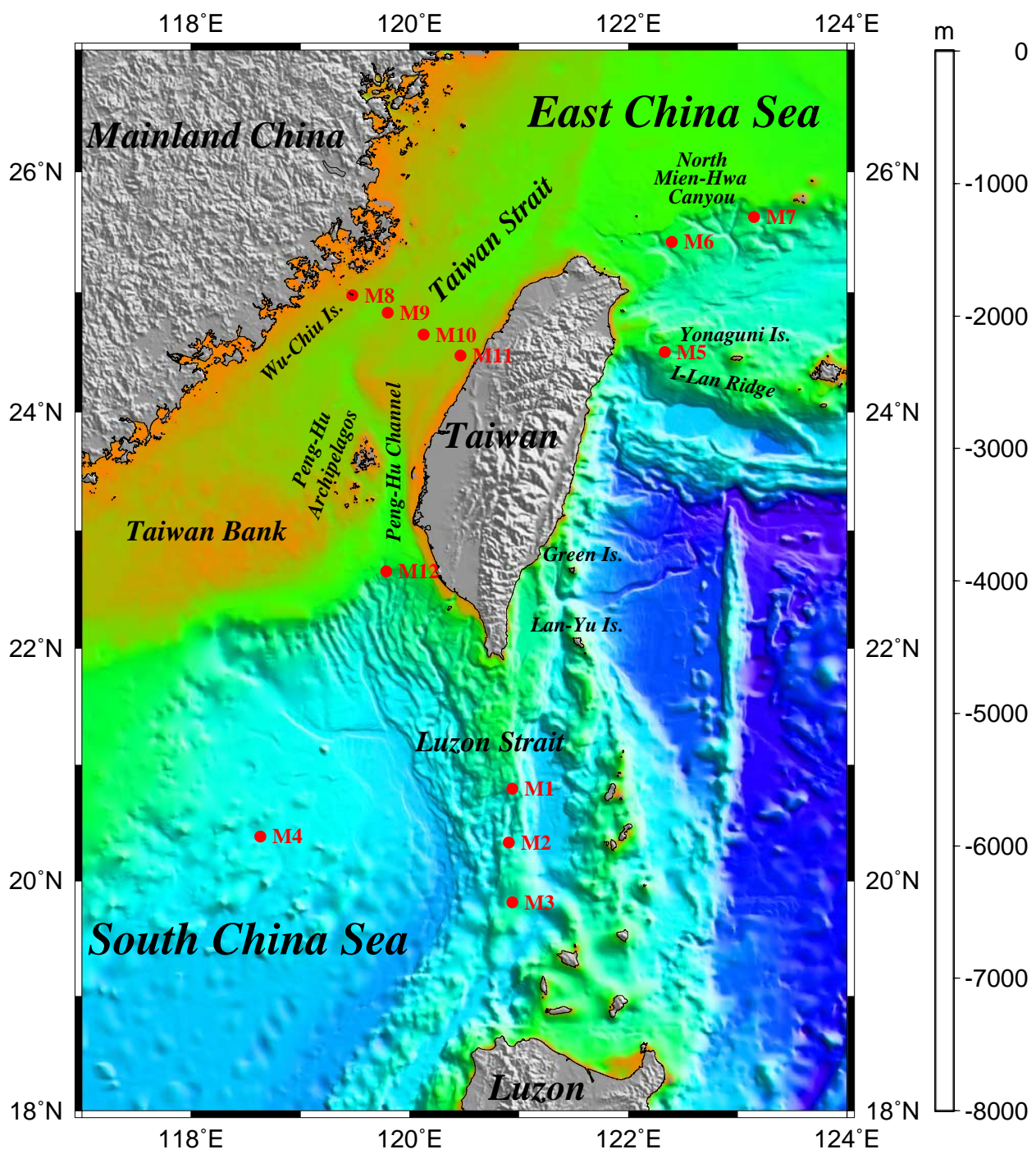

Fig. 1. Bathymetric chart showing areas around Taiwan and mooring locations.

Mainland China measures $200 \mathrm{~km}$ in width, $400 \mathrm{~km}$ in length, and $60 \mathrm{~m}$ in average depth. Only at the southeastern portion of the Taiwan Strait, is the water deeper than $200 \mathrm{~m}$. The funnel-shaped Peng-Hu Channel is located between Taiwan and the Peng-Hu Archipelagos. West of Peng-Hu Channel is the shallow Taiwan Bank, which connects the northern shelf of the South China Sea. The Luzon Strait between Taiwan and Luzon is a passage between the western Pacific Ocean and the South China Sea. Its width is around $400 \mathrm{~km}$ and its maximum depth is $2000 \mathrm{~m}$. On both sides of the Luzon Strait, the water is deep.

The predominant wind system around Taiwan is the monsoon. The northeasterly monsoon prevails November-March, and the southwesterly monsoons prevail from May-September. April and October are transition months. (Chuang and Liang, 1994). The monsoon system is the primary force causing current variation around Taiwan (Wyrtki, 1961). Nitani (1972) described surface currents around Taiwan in summer and winter (see 
Fig. 2). The Kuroshio flows to the north along the coast of Taiwan and the shelf break of the East China Sea. In winter, the Kuroshio intrudes into the South China Sea in the Luzon Strait. In summer, water from the South China Sea enters the western edge of the Kuroshio. East of Taiwan, the width of the Kuroshio is around $100 \mathrm{~km}$, with a maximum speed of around $100 \mathrm{~cm} \mathrm{~s}^{-1}$. The Kuroshio's pathway parallels the shoreline of Taiwan and demonstrates no obvious seasonal variation. South of Peng-Hu Archipelagos, current in the Taiwan Strait flows predominantly northeastward regardless of the seasons. North of the Peng-Hu Archipelagos, the current flows northeastward in summer and southwestward in winter. The seasonal variation is significant only in the Luzon Strait and in the northern Taiwan Strait.

Many oceanographers believe that the Kuroshio intrudes into the South China Sea through the Luzon Strait in winter and stops in summer. This was first described by Wyrtki (1961), and has been re-confirmed by a number of studies (e.g., Shaw, 1989). There are, however, a few studies (e.g., Qu et al., 2000; and $\mathrm{Li}$ and $\mathrm{Wu}, 1989$ ), that indicate that the intrusion of the Kuroshio also occurs in summer. The potential intrusion of the Kuroshio through the Luzon Strait is controversial. Prior studies were largely based upon hydrographic measurements. This study will provide direct current velocity measurements and clarify the issue of Kuroshio intrusion.

Based upon hydrographic measurements and geostrophy, the width, maximum speed, and transport of the Kuroshio east of Taiwan have been estimated in a number of earlier studies. The findings were similar, but contained some notable differences. For example, the transports estimated by Nitani (1972), Chu (1976), and Liu (1983) varied from 19 to $47 \mathrm{~Sv}$. The estimated depth of the Kuroshio varied from a few hundred to a $1000 \mathrm{~m}$. Sun (1987) indicated that the main axis of the Kuroshio varied seasonally, especially north of
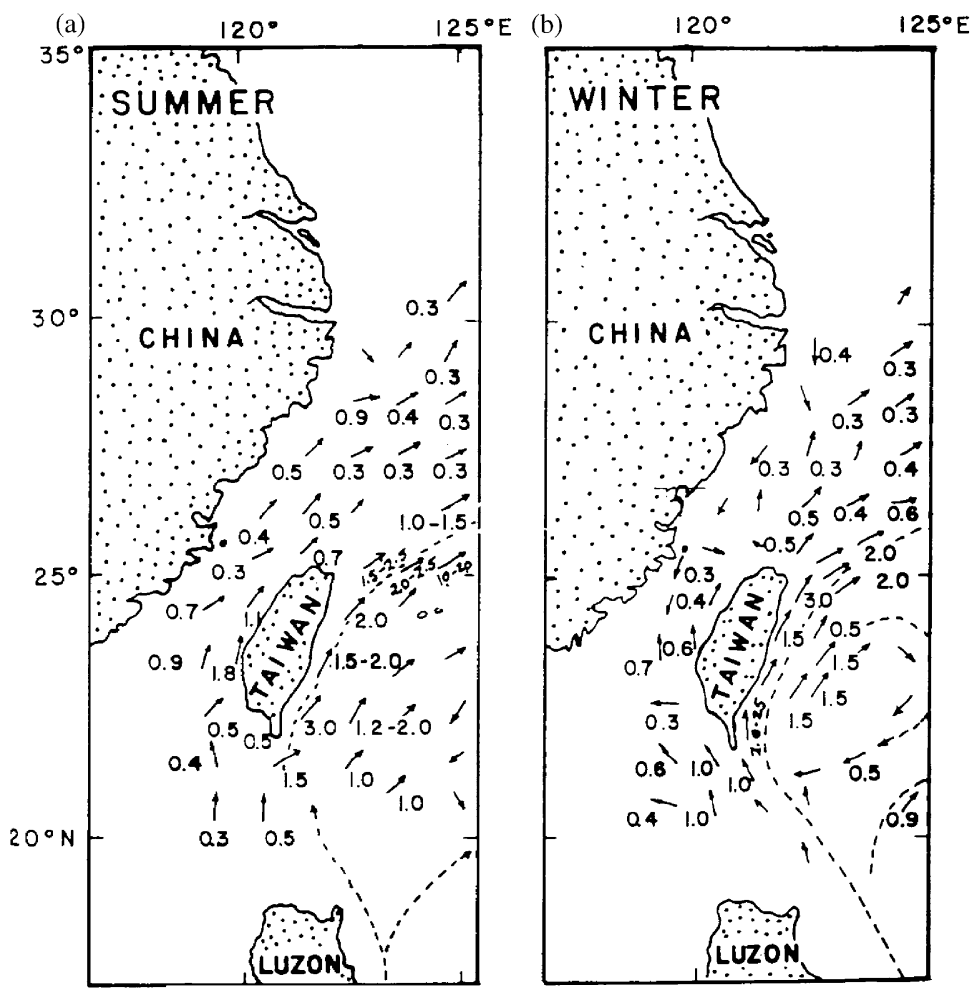

Fig. 2. Current charts in knots: (a) summer, and (b) winter (after Nitani, 1972). 
the I-Lan Ridge, moving close to the coast in winter and away from the coast in summer. Chu (1976) found that the Kuroshio had no clear annual signal but did have a large interannual variation. Recently, moored current velocity measurements along the I-Lan Ridge and altimetry obtained from the TOPEX/POSEDIENT satellite indicated that westward propagating eddies from the Pacific Ocean had a significant impact on the Kuroshio (Yang et al., 1999; Zhang et al., 2001). The transport of Kuroshio reveals significant intra-seasonal variation, with a time scale of 100 days, but with annual variation that is vague.

Analysis of the moored current velocity, temperature, and salinity time series northeast of Taiwan, Tang et al. (2000) suggested that the axis of the Kuroshio migrates not only seasonally, but also intra-seasonally. Such migration has a great impact on the flow pattern north of Taiwan, where the Kuroshio intrudes onto the shelf and interacts with the Taiwan Strait outflow. A southwestward countercurrent, flowing opposite of the Kuroshio, was observed along the shelf edge northeast of Taiwan (Chuang and $\mathrm{Wu}, 1991$; Tang and Yang, 1993; Chuang et al., 1993). As the Kuroshio moves close to shore, it intrudes directly onto the shelf along northeastern Taiwan. The northwestward current prevails in the upper ocean $(<150 \mathrm{~m})$ and the countercurrent is submerged. When the Kuroshio moves away from the shore, the Kuroshio intrudes onto the shelf primarily through the North Mien-Hwa Canyon. A cyclonic eddy forms between the North Mien-Hwa Canyon and Taiwan (Tang et al., 1999). The countercurrent surfaces to complete the annual cycle. Using the Shipboard Acoustic Doppler Current Profiler (SbADCP), Tang et al. (2000) pointed out that the current on the shelf north of Taiwan is primarily northward flowing, regardless of season. The impact of monsoon on the current is minimal.

Chu (1961) claimed that the current in Taiwan Strait is influenced by a number of factors, including the intrusion of the Kuroshio, the South China Sea current, monsoon, and the China coastal current. Wang and Chern (1988) found that the current in the Taiwan Strait was swift and northward under the southwesterly monsoon in summer, while the Mainland China coastal current flowed southward in the northern Taiwan Strait under the northeasterly monsoon. The northward warm and salty Kuroshio water meet the cold, fresh China coastal water around the central Taiwan Strait and a thermohaline front forms, largely prohibiting the Kuroshio from flowing farther north (Wang and Chern, 1989). Chuang (1986) found that the current in the Peng-Hu Channel was northward almost year around. The monsoon does not reverse the current direction except under persistent strong northeasterly monsoon.

This study explores the distribution of threedimensional upper $(<300 \mathrm{~m})$ ocean current velocity around Taiwan. The current velocity data collected during 1991-2000 from the R/Vs Ocean Researcher I, II, and III with the Sb-ADCP were analyzed. Twelve sets of moored current velocity data were used to verify the composite current velocity and to infer the temporal variation of the current. This paper will proceed as follows. Section 2 describes the data and the composite current velocity distribution around Taiwan. Section 3 discusses the qualitative comparison between the composite current velocity and the moored current velocity measurements. Section 4 investigates the three-dimensional upper $(<300 \mathrm{~m})$ ocean current velocity around Taiwan in vertical-meridianal or vertical-zonal sections of current velocity. A discussion and summary are provided in Section 5.

\section{Data and composite current velocity}

The Sb-ADCP measurements used in this study have been provided by the Ocean Data Bank/ National Center for Ocean Research (ODB/ NCOR) of National Science Council (NSC), Republic of China (ROC). Three Taiwanese research vessels, Ocean Researcher I, II, and III collected the Sb-ADCP measurements from 1991 to 2000. In general, the Sb-ADCP was set to measure the current velocity every second and then to record the ensemble average every $1-2 \mathrm{~min}$. The depth bin was $8-16 \mathrm{~m}$, and the depth of range of measurement was from 16 to $320 \mathrm{~m}$. The global positioning system (GPS) recorded the ship location. The ship velocity was estimated based on the 
position time series. To obtain the composite current velocity, the data were processed as follows. The current velocity was first debugged, calibrated, and aligned using the method described by Tang and Ma (1995). To reduce the random error of estimated ship velocity, which was calculated from the ship positions recorded by the GPS, a 30-min running average was applied. The current velocity also was averaged every $30 \mathrm{~min}$. Hereafter, each averaged current velocity is treated as a single data point. The mean ship track during that $30 \mathrm{~min}$ was used as the location of averaged current velocity. The root mean square (rms) error associated with the calibrated and averaged current velocities was less than $\pm 3.5 \mathrm{~cm} \mathrm{~s}^{-1}$. Finally, the velocities were linearly interpolated vertically with $10 \mathrm{~m}$ intervals and averaged horizontally within the grid of size of $0.25^{\circ} \times 0.25^{\circ}$. No further interpolation or smoothing was applied.

Since the Sb-ADCP measurements were not evenly distributed, the number of data points varied in each grid varied. The averaged current velocity in each grid is more representative when there is more data. Conversely, the more data required within each grid, the more fragmented the obtained composite current velocity distribution becomes. A choice has to be made between the minimum requirement of data and integration of composite current velocity. The semidiurnal tidal current is the primary high-frequency fluctuation to bias the composite current velocity in each grid. The semidiurnal tidal velocity has an amplitude of $50 \mathrm{~cm} \mathrm{~s}^{-1}$. Similar to the Sb-ADCP data, the 30 min-averaged tidal velocity, $\bar{u}$, was calculated. To randomly choose $N$ pieces of $\bar{u}$, its average, $\bar{u}_{N}$, would be the noise causing the difference between the composite current velocity and true mean current velocity. Theoretically, $\bar{u}_{N}$ should decrease as $N$ increases. Finally, to repeat the experiment 100 times, the rms of $\bar{u}_{N}$ is calculated. Possible errors caused by the semidiurnal tidal current in the composite current velocity have been estimated. Fig. 3 shows the distribution of numbers of the data, the plot of rms value of $\bar{u}_{N}$ versus the $N$, and the available number of grids versus $N$. The
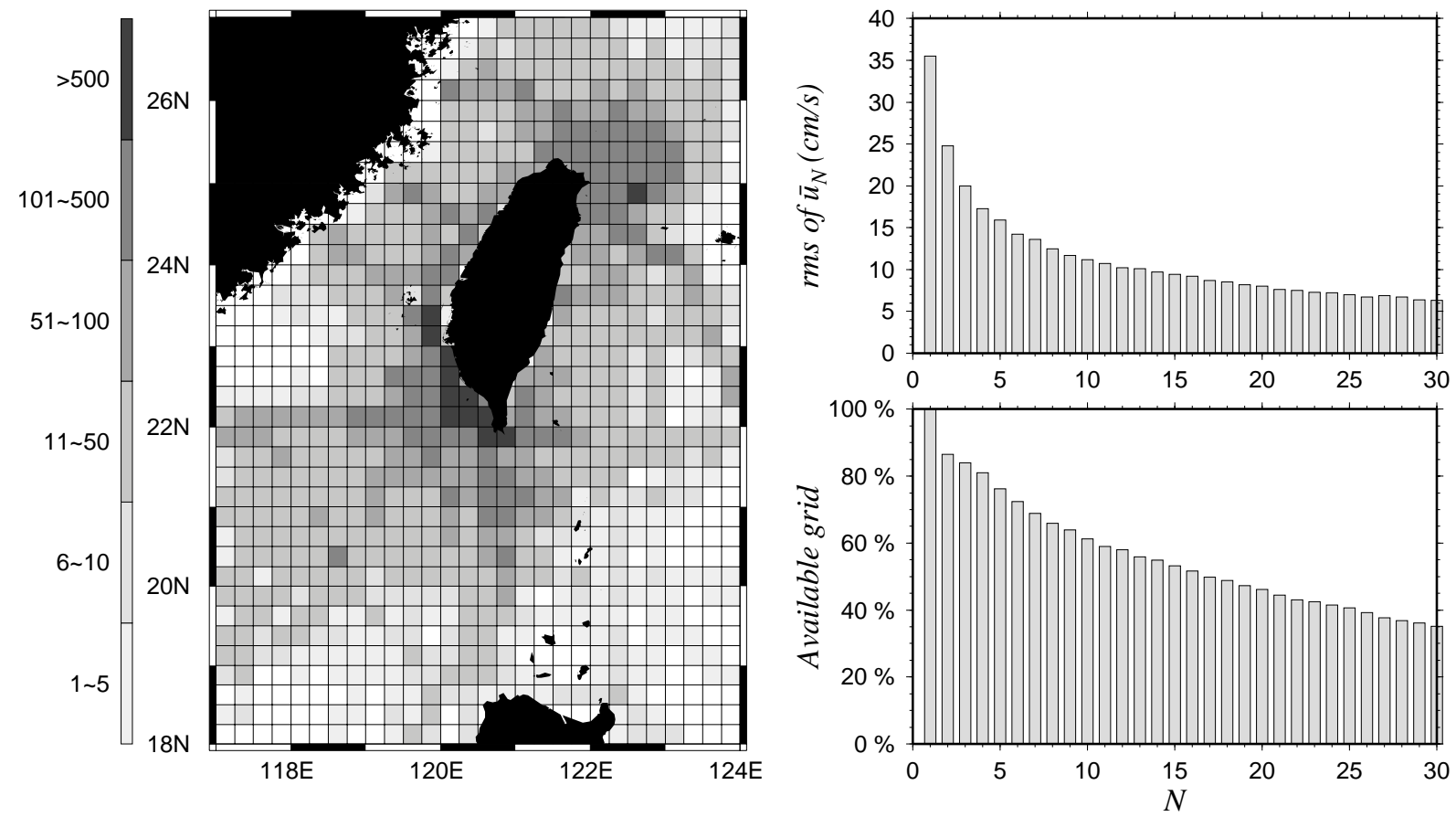

Fig. 3. The left panel denotes the distribution of numbers of data. The right-upper and right-lower panels represent the rms value of the $\bar{u}_{N}$ and the available percentage of grid versus the $N$, respectively. 
numbers of the data in the grids were distributed unevenly. In general, the grid further away from the Taiwan shoreline had less data. The grids had maximum data in the regions of research vessel harbors, at the northern tip and southwestern tip of Taiwan. The rms value deceases rapidly with $N$ increase initially, but gradually flattens out. The available number of grids also decreases with $N$ increase. To remain the relatively integrated distribution of composite current velocity, $N=6$ was chosen as the minimum requirement. The estimated bias caused by the semidiurnal tidal current would be $14 \mathrm{~cm} \mathrm{~s}^{-1}$, around $\frac{1}{4}$ of tidal amplitude. Therefore, we limit our description and discussion on the composite current velocity distribution to qualitative comments.

Fig. 4 shows the composite velocity vectors at 30 and $100 \mathrm{~m}$ around Taiwan. In general, the currents at these tow-depths showed no significant differ- ence. North of Luzon, the Kuroshio flowed to the northwest, and turned clockwise, forming a clockwise path in the Luzon Strait. The main path of the Kuroshio returned to the east of Taiwan, but some Kuroshio water intruded into the northern South China Sea. West of Luzon, the current flowed northeastward and turned counterclockwise to the west as it encountered the Kuroshio. The intruding Kuroshio water and the South China Sea water moved west (seen more clearly at $100 \mathrm{~m}$ ). The westward current seemed to split into two branches. The southern branch was diverse and vague, perhaps due to insufficient data. Results from numerical models (e.g., Shaw and Chao, 1994; Metzger and Hurlburt, 2001) indicate that this is part of the South China Sea circulation, which flows along the edge of the shelf into the central basin of South China Sea. The northern branch (Fig. 4) turned clockwise and

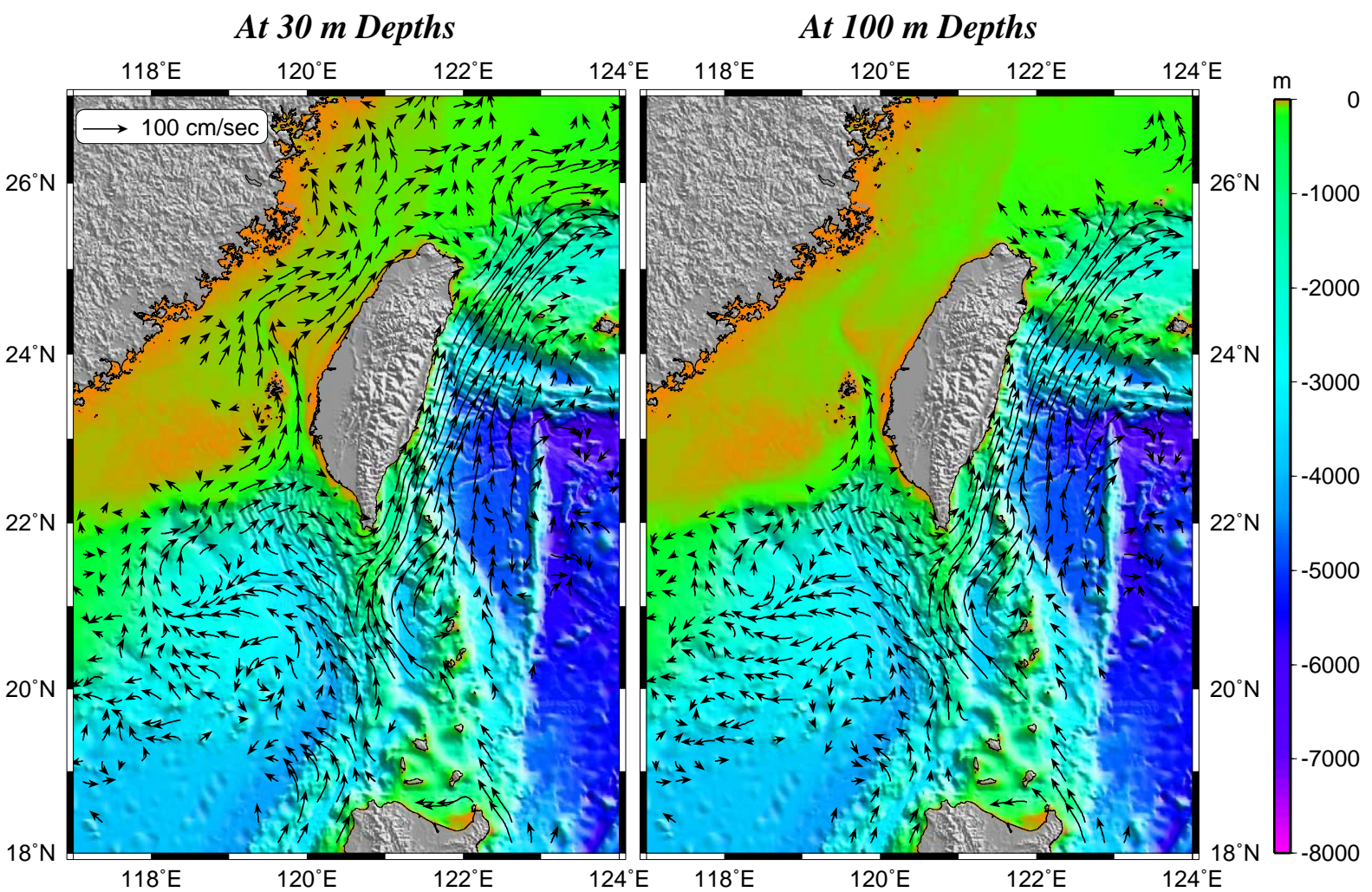

Fig. 4. Composite of the Sb-ADCP current velocity vectors around Taiwan. The left and right panels represent the 30 and $100 \mathrm{~m}$ depths, respectively. 
toward the Kuroshio along the southern tip of Taiwan or else flowed into the Taiwan Strait through the Peng-Hu Channel, producing a clockwise circulation pattern south of the Taiwan Strait.

The current in the Kuroshio is swift along the East Coast of Taiwan. Its maximum speed and width were around $100 \mathrm{~cm} \mathrm{~s}^{-1}$ and $100 \mathrm{~km}$, respectively. Over the I-Lan Ridge, the Kuroshio turned northeastward and left the coast of Taiwan. Only a weak flow was deflected eastward by the I-Lan Ridge, indicating that the I-Lan Ridge did not block the Kuroshio. The Kuroshio flowed northeastwardly along the shelf break after it left Taiwan. Around $26^{\circ} \mathrm{N}$, the zonal shelf break blocked the Kuroshio, and the Kuroshio turned eastward. Some water entered the shelf. On the shelf north of Taiwan, current was weak in the region around $25.3-25.8^{\circ} \mathrm{N}, 121.7-122.2^{\circ} \mathrm{E}$. Outflow of the Taiwan Strait was observed along the northern coast of Taiwan. North of this region, the current velocity was disorderly and confused. This clutter distribution might be caused by the insufficient data and the large bias induced by the tidal currents on the shelf. Tang et al. (2000) claimed that the region of weak current was visible. Because of the seasonal migration of the Kuroshio, the upper $(<150 \mathrm{~m})$ ocean currents reversed during the seasons of northeasterly and southwesterly monsoon, resulting in a weak composite current.

The currents converged at the funnel-shaped Peng-Hu Channel and flowed northward in the Taiwan Strait. As the northward current passed over the northern opening of the Peng-Hu Channel, a ridge separated it into two branches. One branch was deflected westward, following the topography. The other branch flowed over the ridge to the north. Currents with double peaks in the Taiwan Strait were observed north of the ridge, but became vague farther north. Some outflow from the Taiwan Strait followed the northern coast of Taiwan into the Kuroshio. The majority of the Taiwan Strait outflow moved to the north, interacting partially with the intruding Kuroshio.

The composite current velocities at $30 \mathrm{~m}$ under southwesterly and northeasterly monsoons are shown in Fig. 5. During southwesterly monsoon, the flow pattern was similar to the previous velocities distribution. The lack of data in the northeasterly monsoon season was primarily the result of rough sea conditions prohibiting research vessel activities. Current-velocity distributions in the two seasons were similar except a few notable differences. The Kuroshio entered the Luzon Strait primarily during the southwesterly monsoon. Only a small amount of water entered the South China Sea. The Kuroshio intrusion in the Luzon Strait had a larger incident angle during the season of northeasterly monsoon than during the season of southwesterly monsoon. Northeast of Taiwan, a small cyclonic flow seen on the edge of the shelf (centered around $25.5^{\circ} \mathrm{N}, 122.5^{\circ} \mathrm{E}$ ) was observed during the season of southwesterly monsoon. The cyclonic flow disappeared and the Kuroshio moved close to the shelf when the northeasterly monsoon prevailed. In the Taiwan Strait, the current velocity was weaker during the northeasterly monsoon than during the southwesterly monsoon, but the flow was always northeastward. No southward current was observed.

\section{Comparison of moored and shipboard current- velocity measurements}

Twelve sets of moored current-velocity time series, measured by the self-contained Acoustic Doppler Current Profiler (ADCP), are used to affirm the validity of composite current velocity. The seasonal and intra-seasonal variations in current velocity are noted.

Fig. 6 shows four sets of daily current velocity stick time series at M1, M2, M3, and M4, locations of which are shown in Fig. 1. M1-M3 are in the central portion of Luzon Strait and the M4 is around $230 \mathrm{~km}$ west of M2. The current velocity was most often at $100 \mathrm{~m}$. The second segment at M2 was at $140 \mathrm{~m}$ because of a missed count in the mooring rope length. The duration of the measurement at each site was longer than 5 months. In general, the current velocities at varied depths correlated well in the upper $200 \mathrm{~m}$ of the water column, but their amplitude decreased with the depth. The current velocity at M1 and M2 were essentially northwestward, but M1 was more northward than M2. The transition of monsoons 


\section{Southwesterly Monsoon}

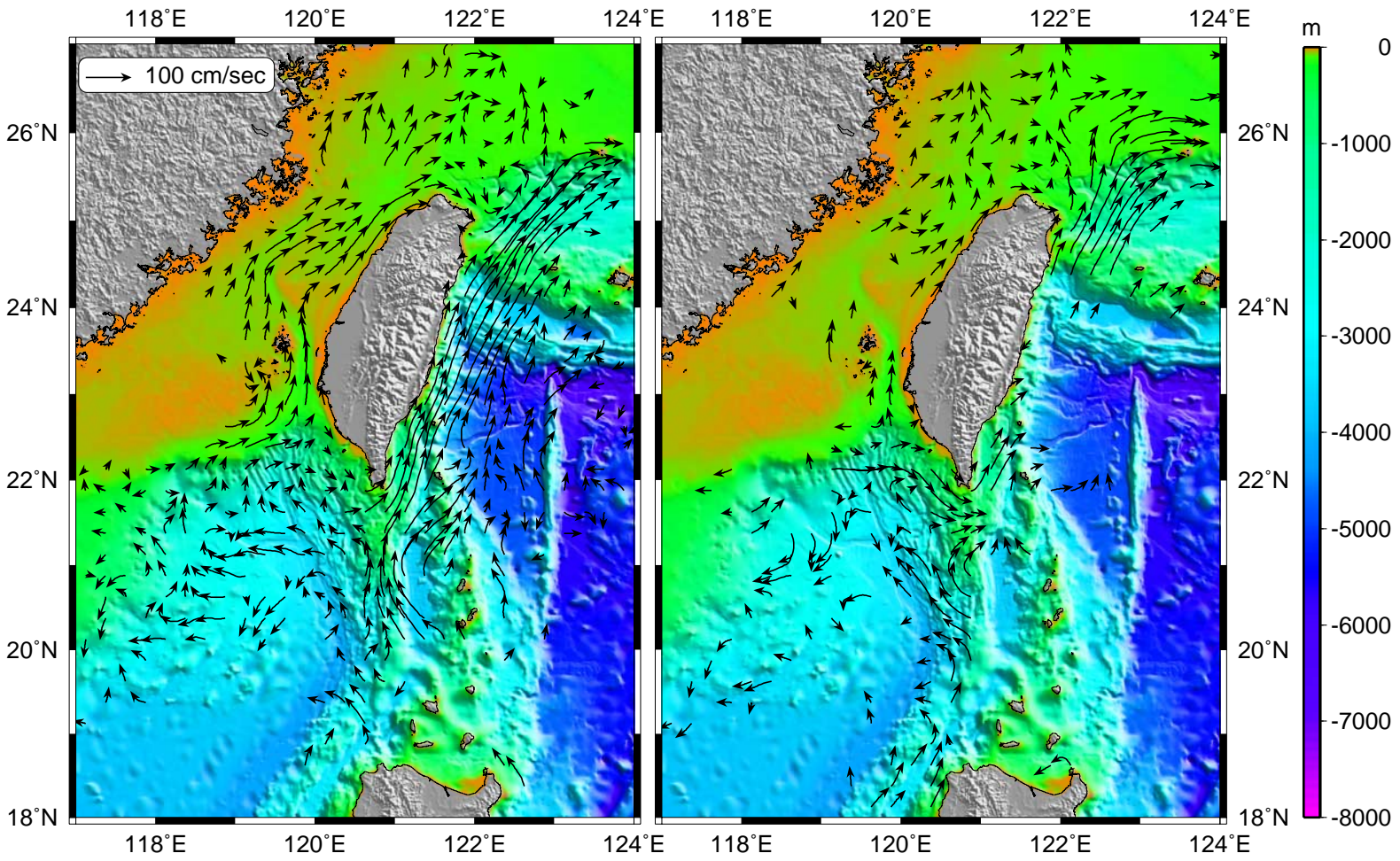

Fig. 5. Composite of the Sb-ADCP current velocity vectors at $30 \mathrm{~m}$ depth around Taiwan. The left and right panels represent the seasons of southwesterly monsoon and northeasterly monsoon, respectively.

from southwest to northeast usually occurred in October (Chuang and Liang, 1994), and had little impact on the current velocity. The current at M1 and M2 indicated that the Kuroshio flowed into the South China Sea steadily and persistently. Differing from the current at M1 and M2, the currents at M3 were weak and varied, frequently from northeastward to northwestward. The currents alternated in and out of the South China Sea. The southern boundary of Kuroshio intrusion could be around M3. The current velocity at M4 also was weak and varied, but it only changed direction from northwest to southwest. A westward component current velocity was consistently observed. The Kuroshio might intrude further to the west.

The variability and mean of current velocities obtained from the moored and shipboard ADCP at each location were compared (Fig. 7). One diagram contains the 30 -min average Sb-ADCP current velocity in the grid where the mooring occurred. The other diagram contains the hourly moored current velocity. The best agreement was obtained at M1, where the current primarily flowed northwest or north-northwest. The mean moored current velocity vector and composite current velocity are nearly identical. At M2, the moored current velocity primarily flowed northwest while the Sb-ADCP current velocity was more diverse. However, both current velocity directions varied in the same range, from north to west (second quadrant). The mean and composite current velocity vectors had similar direction, but the former had larger amplitude. Similarly, the two types of measurement at M3 had some similar characteristics but also had notable differences. Both of them showed they were weaker and had more fluctuations than the current at M1 and M2. 


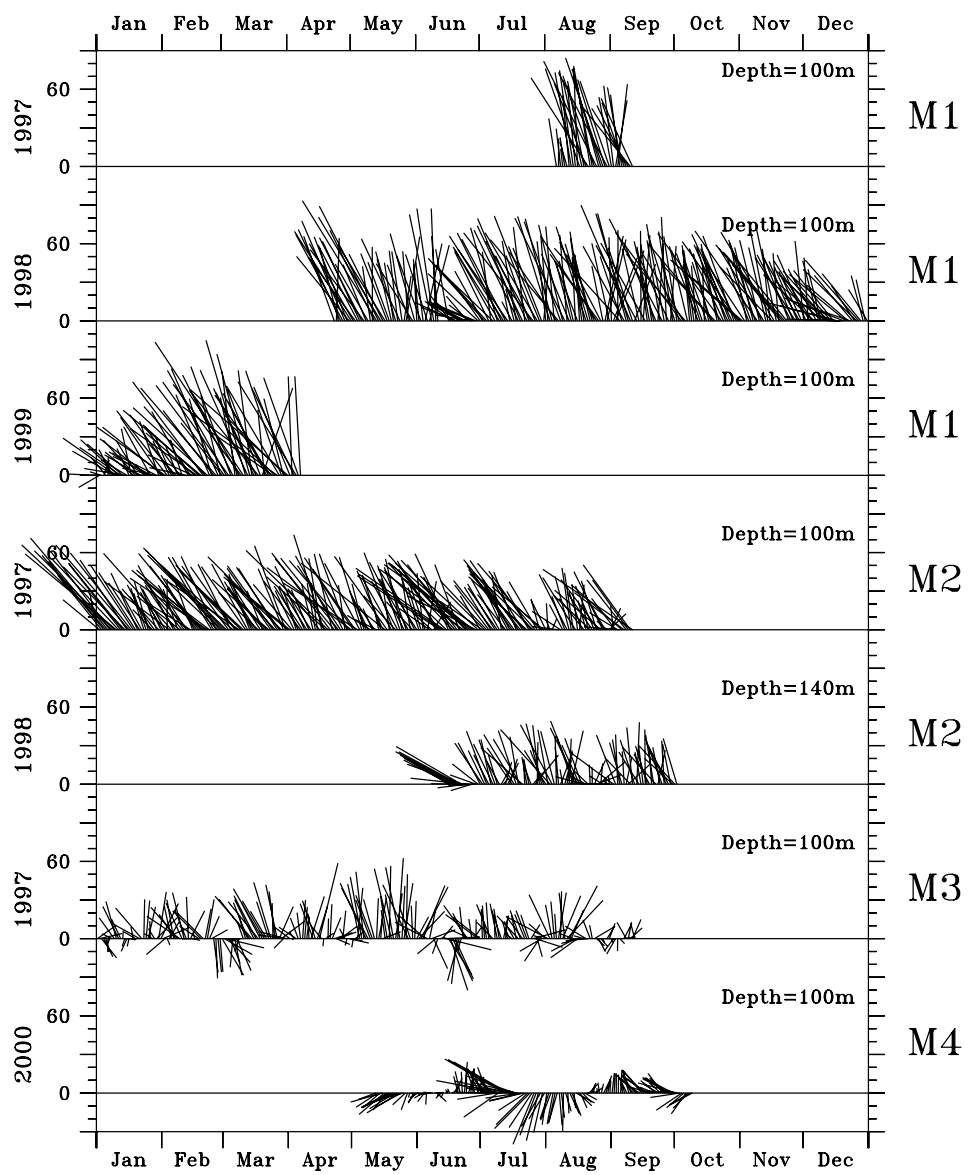

Fig. 6. The stick diagrams of the 36-h low-pass filtered current velocity. The upper to lower panels represent the time series data of M1 in 1997, 1998, and 1999, M2 in 1997 and 1998, M3 in 1997, and M4 in 2000. The current velocity data was primarily at $100 \mathrm{~m}$ depths except the M2 in 1998, which was at $140 \mathrm{~m}$ depth.

Considering the difference in the two sampling methods, it is reasonable to conclude that the two types of measurement agreed qualitatively.

Fig. 8 shows the three daily current-velocity stick time series. The one located at the I-Lan Ridge had the shortest record (less than 2 months). The other two are located at the shelf break northeast of Taiwan. The velocities were at $30 \mathrm{~m}$. At M5, the current was quite stable and flowed to the north-northeast. A similar observation with much longer time series also showed that the current velocity was generally stable, except when the westward-propagated eddy collided with the Kuroshio. The collision occurred about every 100 days (Yang et al., 1999; Zhang et al., 2001). At
M6, the current was first southwestward, and then changed to become northwestward by mid-October. The migration of Kuroshio caused the variation of current velocity. Tang and Yang (1993) and Chuang et al. (1993) described the moored current velocities at M6 in detail. At M7, the current velocity was mainly northeastward, but generally became more eastward in October-April. Tang et al. (2000) claimed the Kuroshio impinged onto the East China Sea shelf around M7. The migration of the Kuroshio also caused the variation of current at M7. However, such variation was not large. In the above three moored current velocities, the large seasonal variation was only seen at M6. 

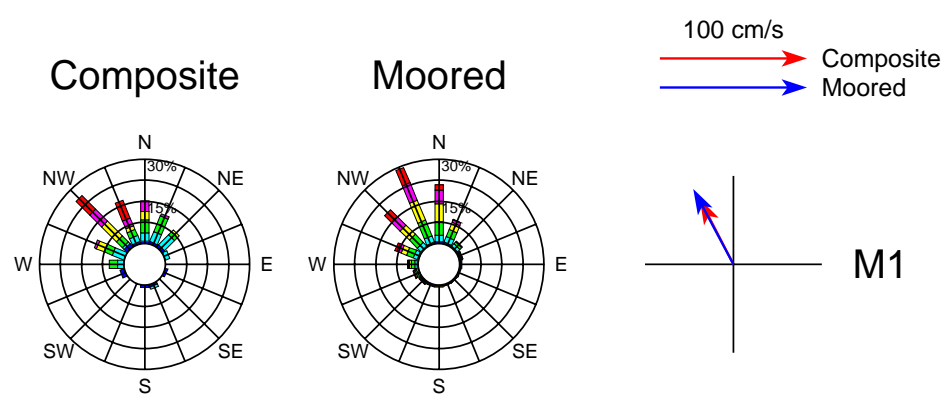

M1
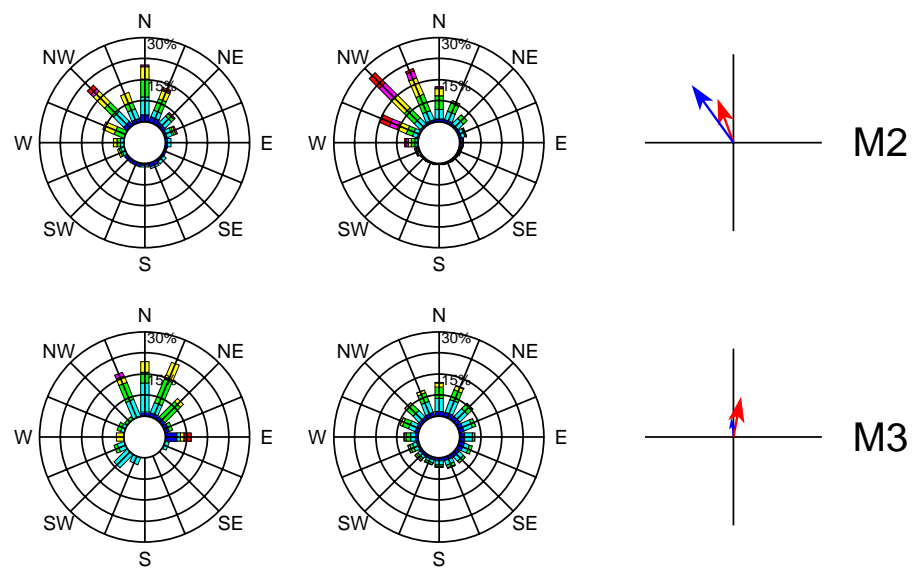

M3
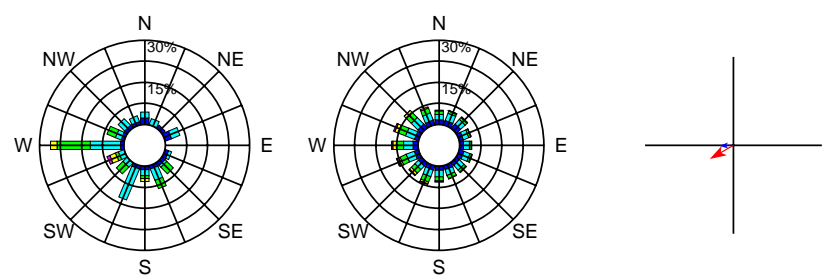

M4

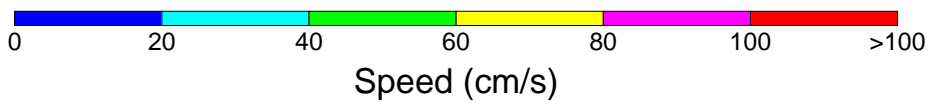

Fig. 7. The rose diagrams and mean current velocities obtained from shipboard and moored ADCP measurement at M1, M2, M3, and M4. The left, central, and right panels represent the rose diagrams of the shipboard and moored ADCP data, and the mean velocities, respectively. The range of rose is $0-30 \%$ with $7.5 \%$ interval.

The comparison between the moored and shipboard ADCP current velocity is shown in Fig. 9. In spite of the record being shorter than 2 months, the moored current velocity at M5 agreed well with the shipboard ADCP current velocity in both variability and mean. At M6, the two types of measurement showed a relatively large disparity; though they also had some similarities. Their variability was roughly in the same range. The mean and composite current velocity vectors had small amplitude and similar direction. The moored and shipboard ADCP current velocity at M7 agreed well in both variability and mean. Generally speaking, the agreement between the two types of measurement was good when the current velocity variation was small, as occurred at M5. When the current velocity had large fluctuations, as at M6, the disparity between the two types of 


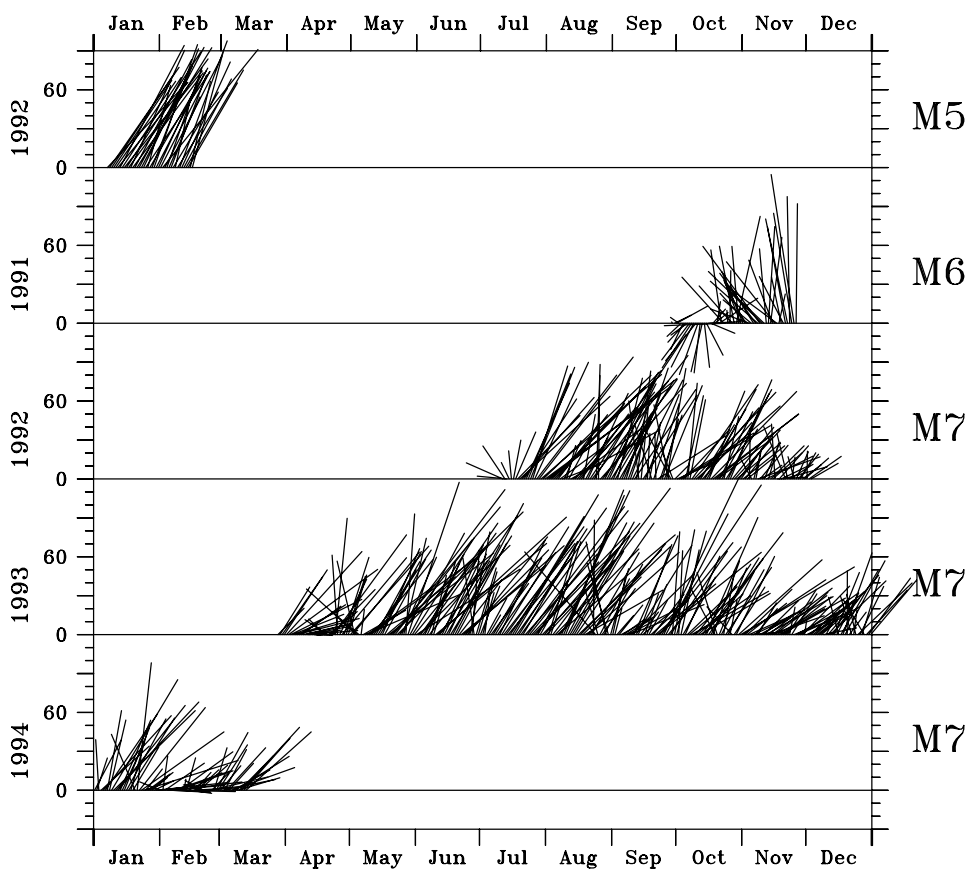

Fig. 8. The stick diagrams of the 36-h low-pass filtered current velocity. The upper to lower panels represent the time series data of M5 in 1992, M6 in 1991, and M7 in 1992, 1993, and 1994. The current velocity data was at a depth of $30 \mathrm{~m}$.

measurement increased. But overall, the shipboard ADCP current velocity properly represents the current velocity - at least, qualitatively.

Fig. 10 shows the five sets, M8, M9, M10, M11, and M12, daily moored current-velocity time series in Taiwan Strait. The velocities were at $30 \mathrm{~m}$. The first four time series were obtained from a mooring array deployed across the Taiwan Strait. The current was observed in the duration of mid-fall to early winter when the northeasterly monsoon prevailed. M12 was located at the southern opening of the Peng-Hu Channel. The current was observed from June-when the southeasterly monsoon prevailed to November, when the northeasterly monsoon was dominant. In general, the current velocities at M8, M9, M10, and M11 fluctuated considerably in the several day time scale. The coherence between the local wind, which was northeasterly, and current velocity was calculated and generally poor (not shown). At M11, the current flowed even against wind for most of the observed period. However, the impact of local wind on the current velocity was still seen by peak-to-peak comparison. The current velocity at M12 primarily flowed with wind moving toward the southwest. The coherence between the current velocities at various stations was also poor. The above result implies that the local wind was not the only dominant external force in the Taiwan Strait; for example, the intruded Kuroshio also could play an important role. At M12, the current velocity persistently flowed into the Peng-Hu Channel, whether the local wind was southwesterly or northeasterly. The northeasterly monsoon, which intensified after October, only caused fluctuation in the current velocity. Again, the local wind poorly correlated with the current velocity. The former inference was reconfirmed: both remote and local forces were important in the Taiwan Strait.

The comparison between the moored and SbADCP current velocities in the Taiwan Strait is shown in Fig. 11. Strong agreement between the two types of measurement was found at M11 and M12. At M8, M9, and M10, a large disparity was observed. The disparity could arise from a number 

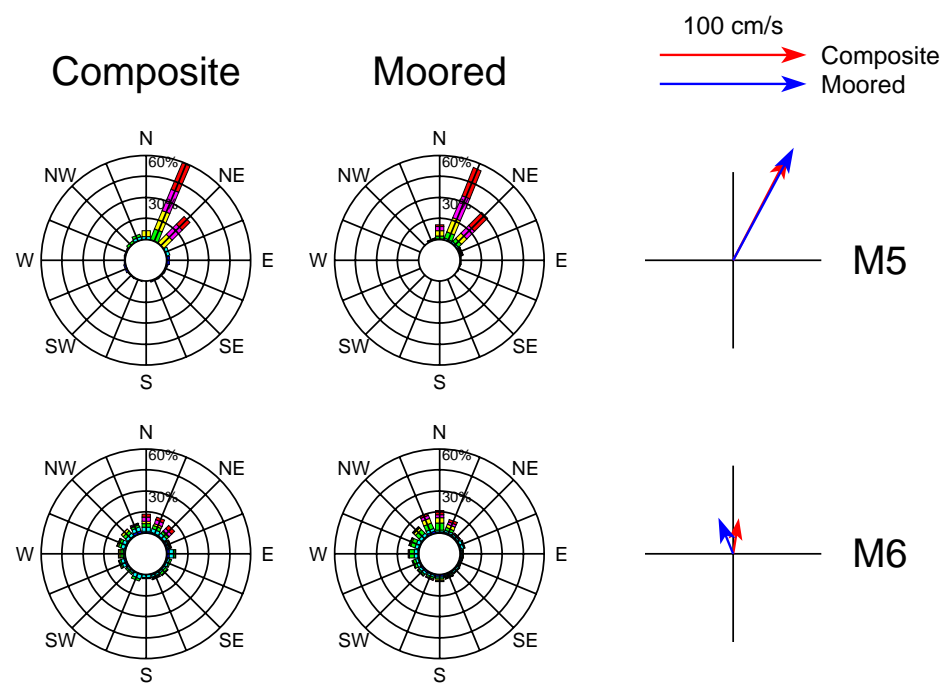

M5
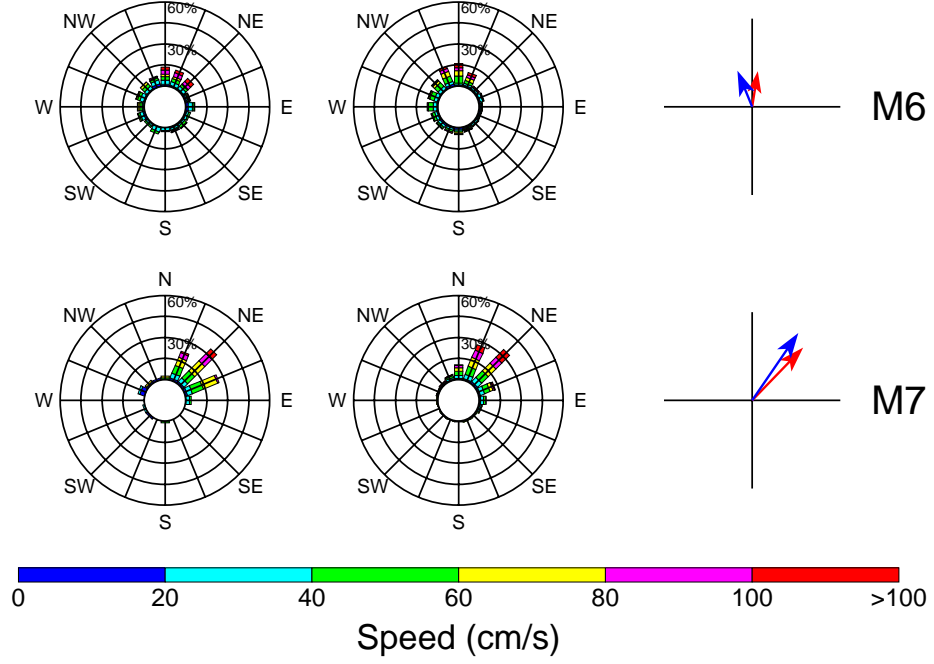

Fig. 9. Same as Fig. 7 except at M5, M6, and M7. The range of rose is $0-60 \%$ with $15 \%$ interval.

of factors. For example, the data were sparse, especially in the western Taiwan Strait. The SbADCP data were lacking when the northeasterly monsoon was large. There was no moored current velocity during the southwesterly monsoon season. The large semidiurnal tidal current velocity also could be a source of error for the composite current velocity.

The composite current velocity might inadequately represent the current where there was a large current-velocity variation. However, this type of current is limited around Taiwan. The above comparison between moored and Sb-ADCP current velocity indicates that the composite current velocity obtained from the Sb-ADCP measurements represents the current around Taiwan qualitatively, but not quantitatively.

\section{Vertical sections of current velocity}

Fig. 12 shows the vertical sections of zonal $(U)$ and meridional $(V)$ components of current velocity along the Luzon Strait and along $21^{\circ} \mathrm{N}$. The latitude-vertical section of $U$ along the Luzon Strait showed that the eastward/westward current alternately occurred from northern Luzon to southern Taiwan. The westward current occupied a larger area and had larger amplitude than the eastward current. The largest westward current occurred in the central-northern Luzon Strait, while the largest eastward current appeared at the southern tip of Taiwan. The northward current dominated in the $V$ section. Its maximum speed was over $50 \mathrm{~cm} \mathrm{~s}^{-1}$. The southward current was only observed at the tips of northern Luzon and 


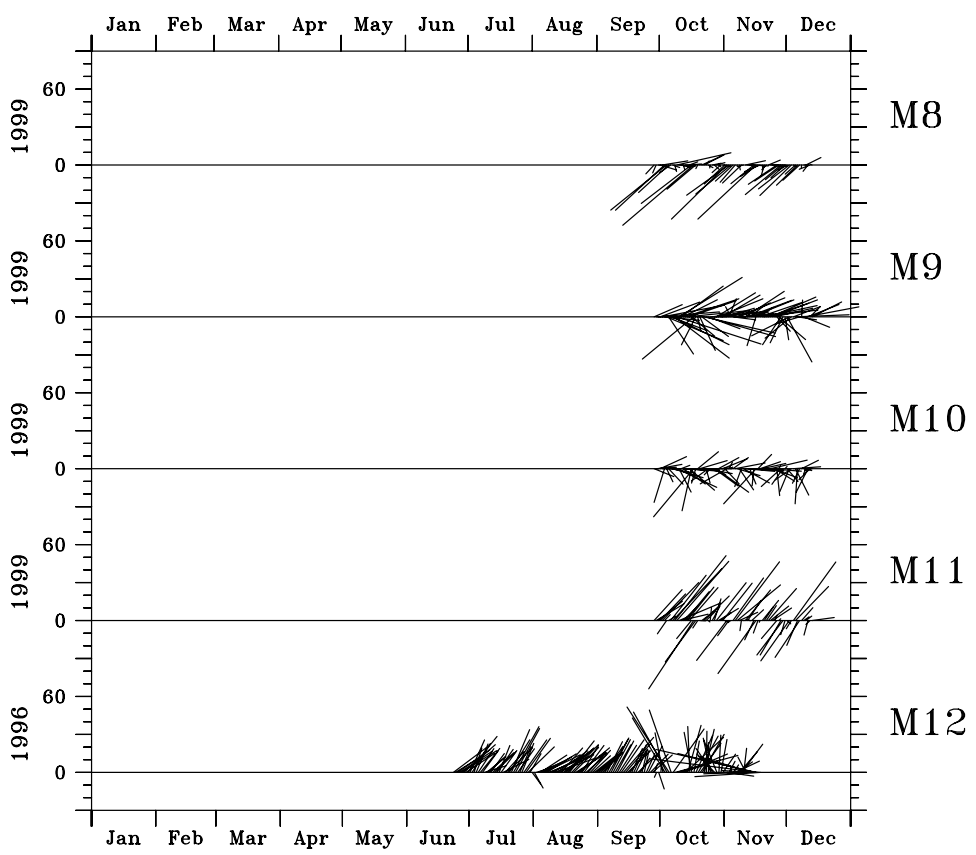

Fig. 10. The stick diagrams of the 36-h low-pass filtered current velocity. The upper to lower panels represent the time series data of M8, M9, M10, and M11 in 1999, and M12 in 1996. The current velocity data was at a depth of $30 \mathrm{~m}$.

southern Taiwan. The westward current, indicating that the water intruded into the South China Sea from Pacific Ocean, generally accompanied the large northward current. The intruded current should primarily be the Kuroshio. The South China Sea outflow at southern Luzon Strait could retroflex back to the South China Sea though the central Luzon Strait, but its amount was small. The zonal volume transport, calculated by simply integrating the $U$ along the section, was around $-3 \mathrm{~Sv}$ to the west. A smaller, but also negative, value was obtained by using the Sb-ADCP measurement collected only in the season of southwest monsoon. Apparently, the Kuroshio intruded into the South China Sea even in the southwest monsoon season. Although the transport of Kuroshio intrusion was only estimated qualitatively, the moored current velocity supported such an inference because the Kuroshio intrusion occurred persistently. The earlier belief that no Kuroshio intrusion occurred in the Luzon Strait in summer might need to be reconsidered.

Along $21^{\circ} \mathrm{N}$, the longitude-vertical section of $U$ was primarily westward of the Luzon Strait signifying that the intruded Kuroshio flowed continuously westward. The maximum westward speed was around $30 \mathrm{~cm} \mathrm{~s}^{-1}$. East of the Luzon Strait, the $U$ was fragmented, with eastward/ westward current reciprocally shown. The northward current dominated in the $V$ section. A weak southward current was observed west of $119^{\circ} \mathrm{E}$. East of this southward current, the northward current extended from $119^{\circ} \mathrm{E}$ to $121.75^{\circ} \mathrm{E}$. The region was wide - around $300 \mathrm{~km}$. The maximum northward current, around $60 \mathrm{~cm} \mathrm{~s}^{-1}$ was in the Luzon Strait. East of this northward current, the $V$ was negative/positive reciprocally. The Kuroshio became vague around the Luzon Strait, possibly because the western boundary current is deficient in its western continental boundary. Local topography also might play a role. A few islands, which lie near the $122^{\circ} \mathrm{E}$ parallel with the Luzon Strait, might cause the spatial current fluctuation east of Luzon Strait.

East of Taiwan, four longitude-vertical currentvelocity sections along $22^{\circ} \mathrm{N}, 23^{\circ} \mathrm{N}, 24^{\circ} \mathrm{N}$, and $25^{\circ} \mathrm{N}$ are shown in Fig. 13. The Kuroshio dominated all four sections. On the southernmost 

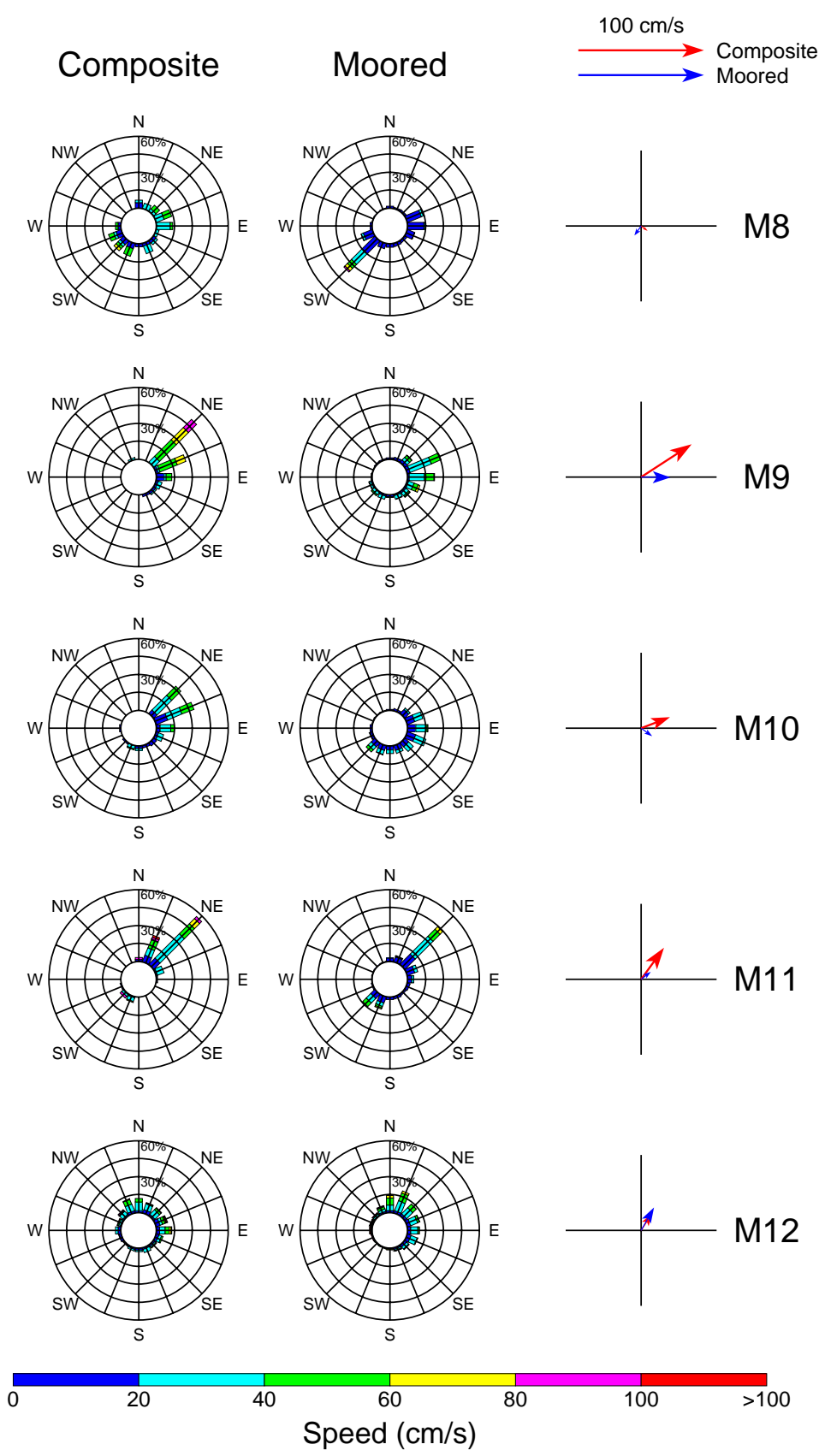

Fig. 11. Same as Fig. 9 except at M8, M9, M10, M11, and M12.

section (along $22^{\circ} \mathrm{N}$ ), the $U$ was weak. It was primarily positive (eastward) between Taiwan and Lan-Yu near $121.5^{\circ} \mathrm{E}$. East of Lan-Yu, the $U$ gradually turned to negative (westward). A weak eastward component was seen again east of $124^{\circ} \mathrm{N}$. The $V$ was chiefly positive (northward) and had two maximum velocity cores located on two sides of Lan-Yu, respectively. The western core with maximum speed over $90 \mathrm{~cm} \mathrm{~s}^{-1}$ was near the surface. The eastern core with maximum speed 

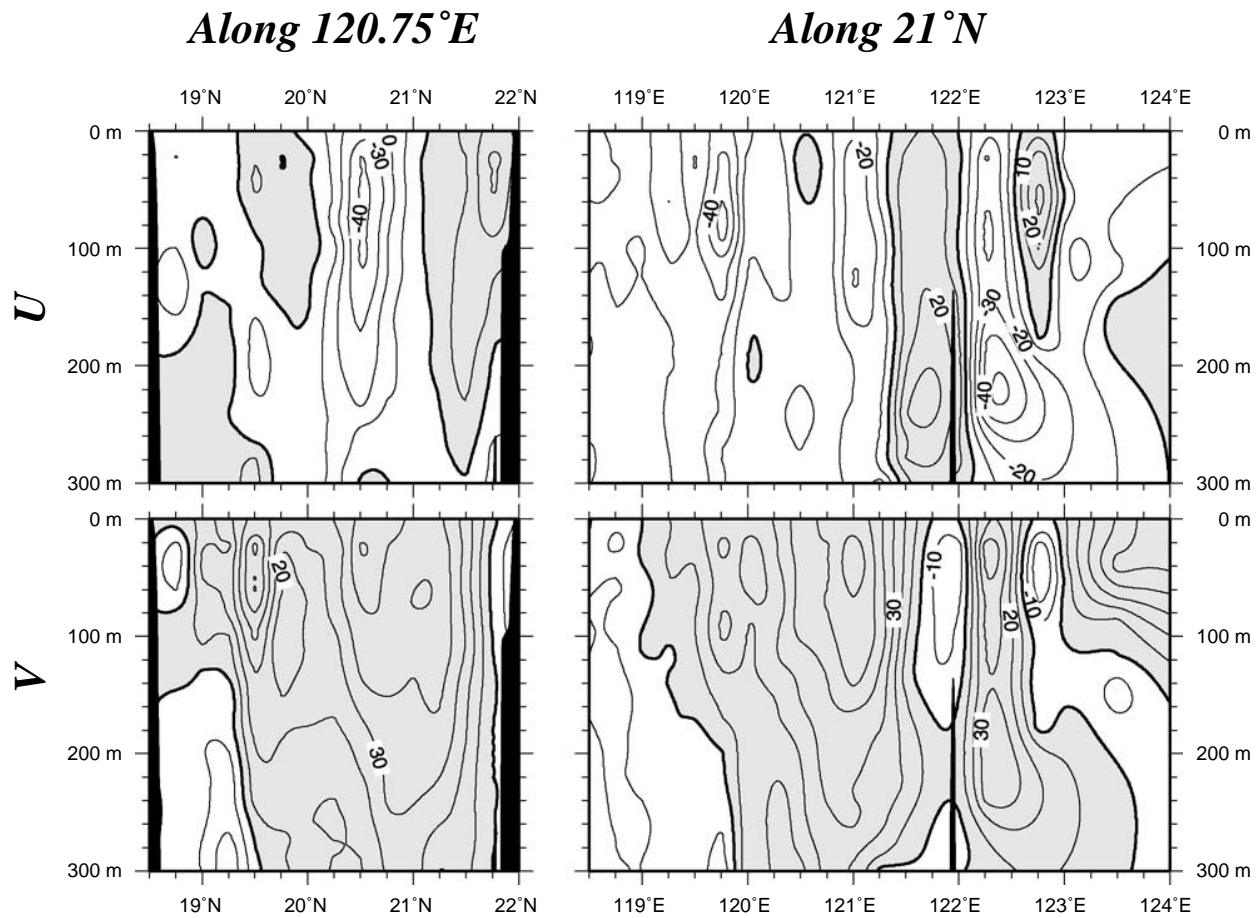

Fig. 12. Vertical sections of composite Sb-ADCP current velocity of zonal $(U)$ and meridional $(V)$ components along the $120.75^{\circ} \mathrm{E}$ and $21^{\circ} \mathrm{N}$ are show in left and right panels, respectively. The depth range is from the surface to about $300 \mathrm{~m}$. The continental shelf is darkened. The values are contoured at intervals of $10 \mathrm{~cm} \mathrm{~s}^{-1}$. The zero contour appears in heavy line. Portions of positive values are shaded.

around $70 \mathrm{~cm} \mathrm{~s}^{-1}$ was at subsurface $(70 \mathrm{~m})$. The eastward current generally accompanied the western core while the westward current accompanied the eastern core. This implies that the two cores eventually combined together as the Kuroshio flowed further north. The feature of double maximum velocity cores could be caused by the local topography or the fact that the split Kuroshio in the Luzon Strait had not fully reunited. The southwestward countercurrent was observed close to Taiwan at subsurface as well as east of Kuroshio.

The velocity section along $23^{\circ} \mathrm{N}$ was similar to it along $22^{\circ} \mathrm{N}$. The Kuroshio had double velocity cores. The western core had greater speed and was at surface, while the eastern core had smaller speed and was at subsurface. Again, the cores seemed to merge further north. The subsurface countercurrent close to Taiwan was barely observed. West of the Kuroshio, the countercurrent was weaker than that at the section of $22^{\circ} \mathrm{N}$.
The two velocity cores merged into a single core at the section of $24^{\circ} \mathrm{N}$, south of I-Lan Ridge. The $U$ and $V$ were mostly positive, but the $V$ had much greater amplitude. The negative $U$ and $V$ were only seen at subsurface close to Taiwan. The Kuroshio was mainly northward; its eastward component was small. I-Lan Ridge is quite close to the section of $24^{\circ} \mathrm{N}$, but its impact on the Kuroshio was not observed here.

The velocity at section of $25^{\circ} \mathrm{N}$, north of I-Lan Ridge, showed that the $U$ and $V$ were still primarily positive, but the amplitude of $U$ increased and the amplitude of $V$ decreased. This suggests that the Kuroshio was deflected as it flowed over the I-Lan Ridge. The countercurrent was observed close to Taiwan. Its southward component velocity extended to the surface, indicating the Kuroshio departed from Taiwan coast. Such separation could be due to the deflection of Kuroshio. Using the similar data, Tang et al. (2000) found that the 

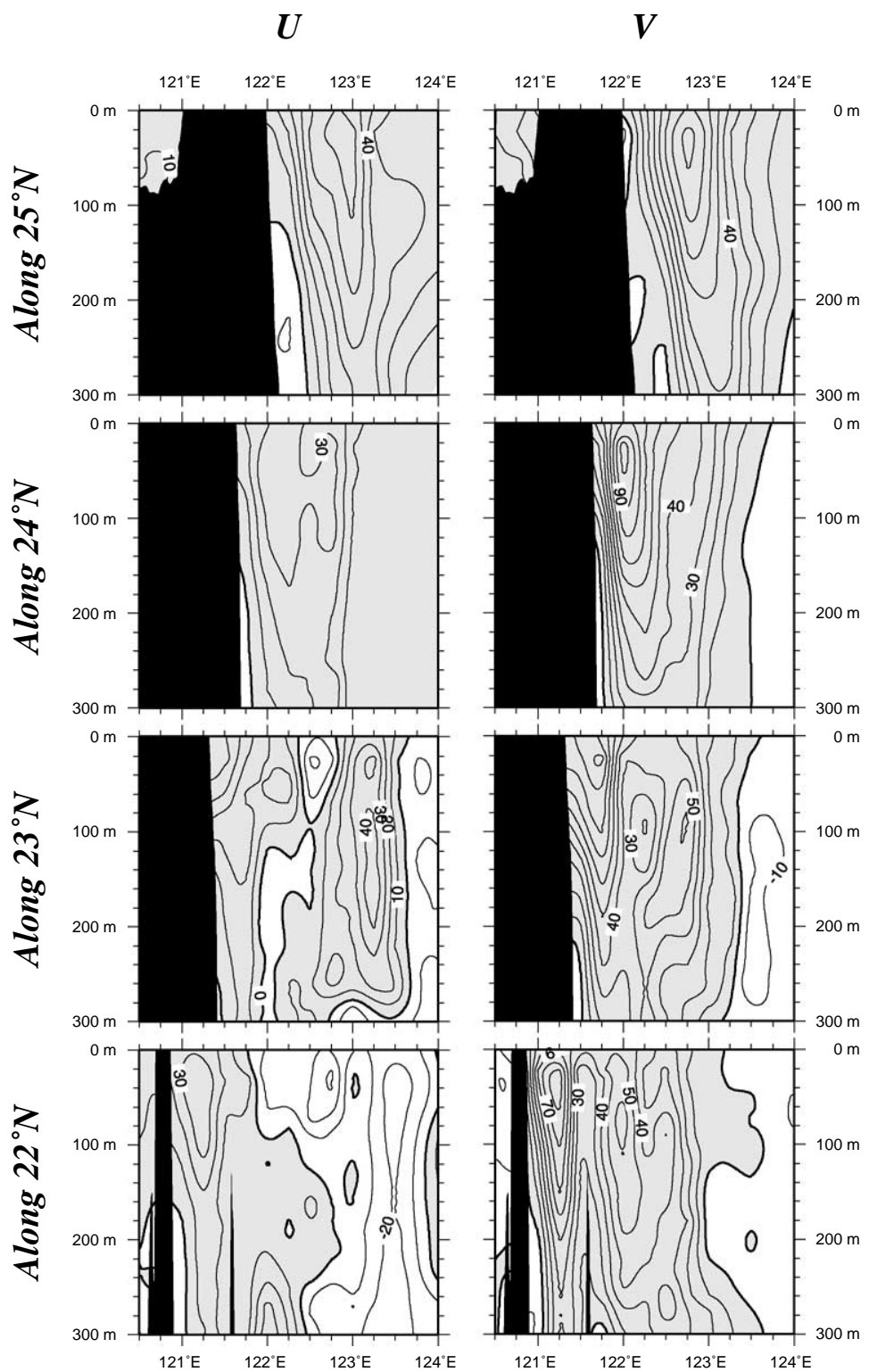

Fig. 13. Vertical sections of composite Sb-ADCP current velocity of zonal $(U)$ and meridional $(V)$ components along the $22^{\circ} \mathrm{N}, 23^{\circ} \mathrm{N}$, $24^{\circ} \mathrm{N}, 25^{\circ} \mathrm{N}$ east of Taiwan are show in left and right panels, respectively. The depth range is from the surface to about $300 \mathrm{~m}$. The continental shelf is darkened. The values are contoured at intervals of $10 \mathrm{~cm} \mathrm{~s}^{-1}$. The zero contour appears in heavy line. Portions of positive values are shaded.

Kuroshio migrated seasonally, but the migration was small.

Fig. 14 shows the width, main axis, and upperocean $(<300 \mathrm{~m})$ northward volume transport of Kuroshio. The $10 \mathrm{~cm} \mathrm{~s}^{-1}$ isotach of northward velocity was used as an indicator for the bound- aries of the Kuroshio. The maximum northward speed defined the main axis of the Kuroshio. The linear integration was applied to estimate the northward volume transport. From south to north, the main axis of the Kuroshio was close to the coast of Taiwan south of I-Lan Ridge. It 


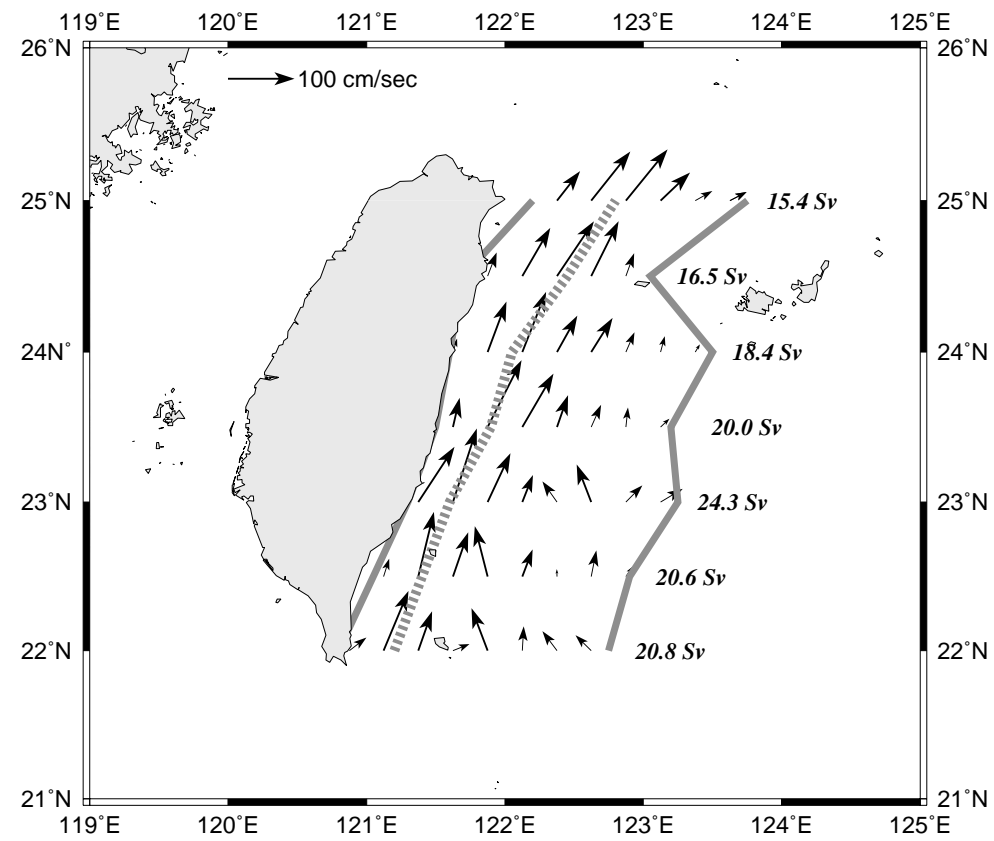

Fig. 14. The upper ocean $(<300 \mathrm{~m})$ northward volume transport of Kuroshio and composite Sb-ADCP current velocity vectors at $30 \mathrm{~m}$ depth east of Taiwan. Bold and dashed lines indicate the width and main axis of Kuroshio.

departed from the coast as it flowed over the I-Lan Ridge. The maximum speed $\left(>100 \mathrm{~cm} \mathrm{~s}^{-1}\right)$ along the main axis of the Kuroshio showed little variation. The width of the Kuroshio was around $170 \mathrm{~km}$, but narrowed to $120 \mathrm{~km}$ on I-Lan Ridge. The northward volume transport of Kuroshio demonstrated no significant and systematic change south of I-Lan Ridge. It reduced as the Kuroshio approached and flowed over the I-Lan Ridge. The reduction of the northward transport of Kuroshio was essentially caused by deflection of Kuroshio. A part of northward transport turned to eastward transport. The values of northward volume transport are listed as a reference only since the composite current velocity might be inappropriate to make a quantitative estimate. However, the present estimated volume transport in the I-Lan Ridge agreed well with the transport estimated by Johns et al. (2001), whose estimate was obtained from an array of moored current velocity time series.

In summary, the Kuroshio flowed primarily northward along the eastern coast of Taiwan. East of southern Taiwan, the Kuroshio split, but gradually re-united. As the Kuroshio flowed over the I-Lan Ridge, it was deflected eastwardly. The velocity became more eastward. The Kuroshio departed from the Taiwan coast. A subsurface countercurrent close to the island was consistently observed. It surfaced north of I-Lan Ridge.

Since the previous studies indicated that the current along the shelf break northeast of Taiwan had noticeable seasonal variations, Fig. 15 shows the $U$ and $V$ sections along $25.5^{\circ} \mathrm{N}$ in the seasons of southwesterly and northeasterly monsoon. The seasonal variation was observed. Regardless of the seasons, a negative $U$ occurred around shelf break. It clearly separated the main stream of Kuroshio and the current on the shelf. Corresponding to this negative $U$, the $V$ was positive and negative in the upper and lower water column, respectively. However, this distribution of $V$ varied seasonally. The negative $V$ occurred in the deep water in the northeasterly monsoon season, but it extended upwardly to near surface in the southwesterly monsoon season. This result agrees with the earlier finding (Tang et al., 2000) that the subsurface southwestward countercurrent at the shelf break 


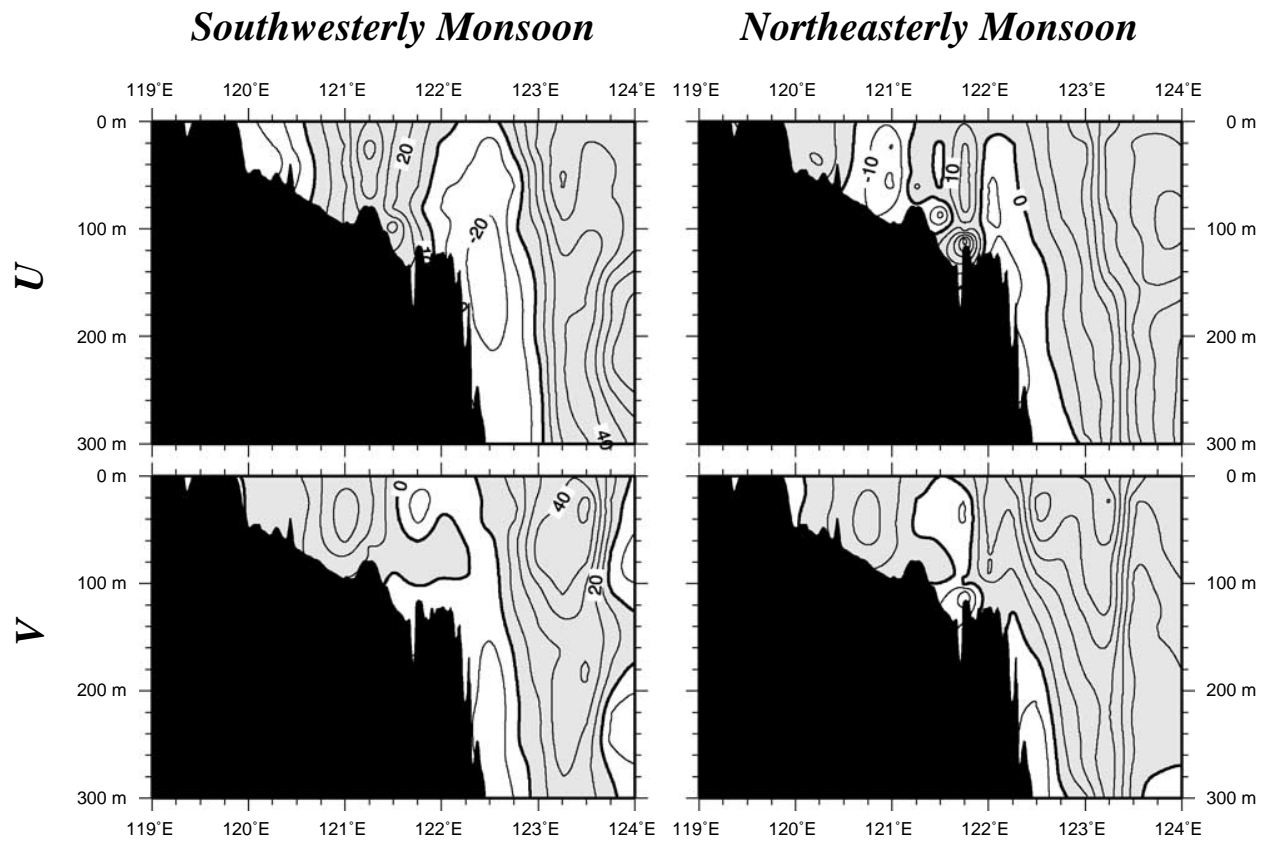

Fig. 15. Vertical sections of composite Sb-ADCP current velocity of zonal $(U)$ and meridional $(V)$ components along the $25.5^{\circ} \mathrm{N}$ in seasons of southwesterly monsoon and northeasterly monsoon are show in left and right panels, respectively. The depth range is from the surface to about $300 \mathrm{~m}$. The continental shelf is darkened. The values are contoured at intervals of $10 \mathrm{~cm} \mathrm{~s}^{-1}$. The zero contour appears in heavy line. Portions of positive values are shaded.

northeast of Taiwan was submerged when the northeasterly monsoon intensified. East of the countercurrents, both $U$ and $V$ were positive. The northeastward Kuroshio was presented and showed much more complicated spatial velocity distribution than it did east of Taiwan. The locations of maximum velocity cores of $U$ and $V$ were different, implying that the Kuroshio was branching. The influence of the zonal-running shelf break north of this section on the Kuroshio was noted. A part of the Kuroshio in the upper ocean flowed northward or even northwestward intruding onto the shelf. The shelf blocked the subsurface Kuroshio, which flowed northeastward or even eastward. The Kuroshio also varied significantly with monsoons. In the southwesterly monsoon season, the Kuroshio was weak and its maximum speed core was at subsurface. In the northeasterly monsoon, the weak Kuroshio intensified and the subsurface core nearly disappeared. However, the feature of the Kuroshio having greater speed in winter than summer could be meaningless if we give consideration to the seasonal migration. When the Kuroshio moved off shore in the southwesterly monsoon season, it may be that only a portion of the Kuroshio was observed. Such migration also caused more Kuroshio intrusion northwestwardly onto the shelf in the northeasterly monsoon season.

On the shelf north of Taiwan, the current was generally complicated. The complicated flow distribution could be related to the intrusion of Kuroshio, Taiwan Strait outflow, and their interaction. However, the large semidiurnal tidal current velocity on the shelf could result in a large error in the computed composite current velocity. Such an error could further increase the complication of current velocity distribution. Therefore, there is no detailed description of the spatial current velocity distribution on the shelf. Nevertheless, the current on the shelf seems to prefer flowing northeastward regardless of season. The local wind could not be the only dominant force on the shelf north of Taiwan.

Fig. 16 shows four velocity vertical sections along $22^{\circ} \mathrm{N}, 23^{\circ} \mathrm{N}, 24^{\circ} \mathrm{N}$, and $25^{\circ} \mathrm{N}$ in the Taiwan 
Strait. On the southern opening of Taiwan Strait (section along $22^{\circ} \mathrm{N}$ ), the $V$ was positive and negative in the western and eastern portions, respectively, while the positive $U$ dominated nearly the entire section. This type of velocity distribution supports the former finding, a clockwise circulation south of Taiwan Strait. In the Peng-Hu Channel, the current velocity was mainly northward in the deep channel where the $U$ was weak. West of the deep channel, the $U$ was

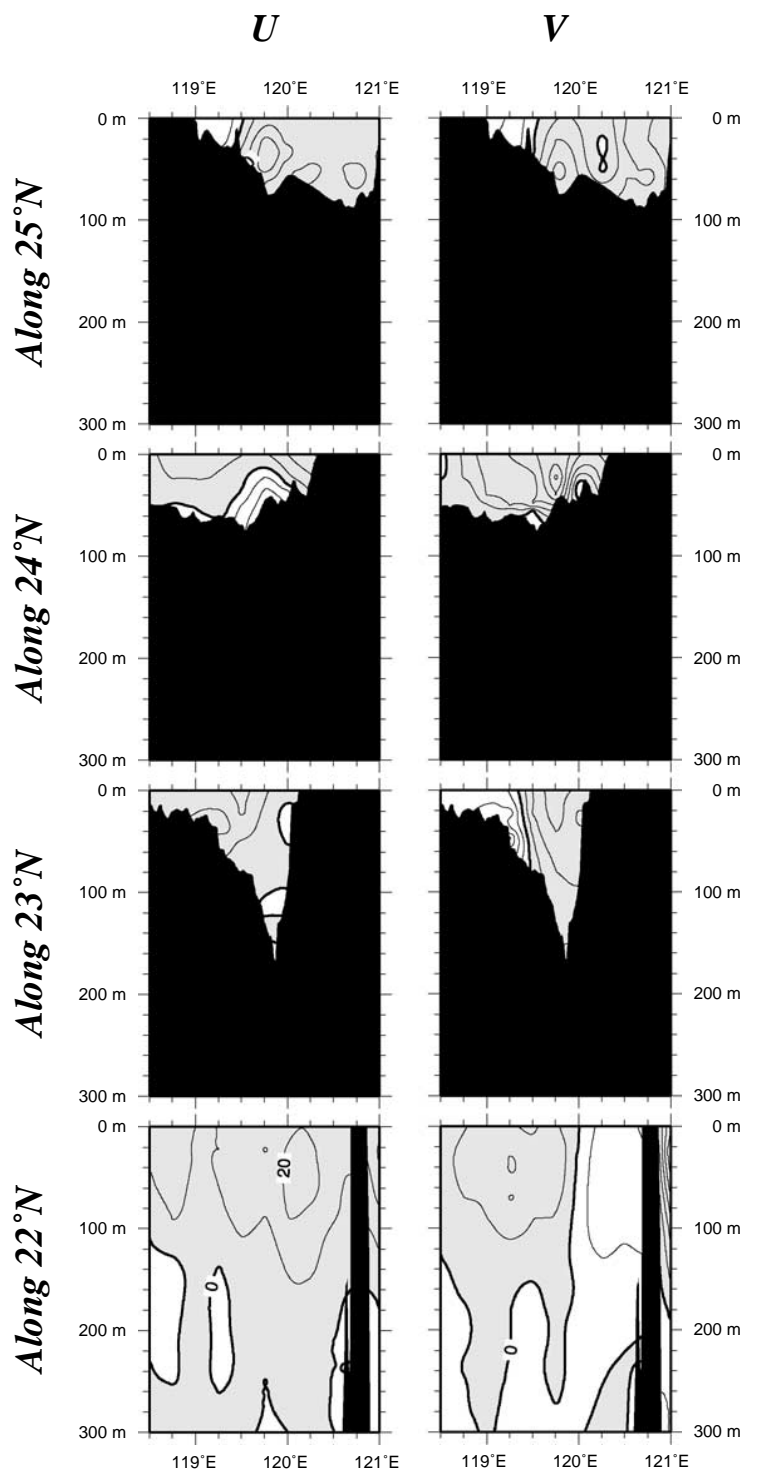

Fig. 16. Same as Fig. 13 except in Taiwan Strait. positive and had relatively simple distribution. The $V$ varied from positive to negative and then to positive again. A couple of maximum speed cores were near bottom. The Peng-Hu Archipelagos north of this section could be responsible for this complicated flow distribution. However, the net northward transport was positive, indicating that the water flowed into the Taiwan Strait. Along the section of $24^{\circ} \mathrm{N}$, the $U$ was negative at the shallow end of the funnel-shaped Peng-Hu Channel, which curved northwestward. It was positive at two sides of the end. The $V$ was primarily positive, except in the region close to Mainland China. The region's large $V$ and negative $U$ nearly coincided, indicating that the Peng-Hu Channel conducted the water flow into the Taiwan Strait. Near the northern opening of the Taiwan Strait (section of $25^{\circ} \mathrm{N}$ ), both $U$ and $V$ were principally positive. Their negative values were seen in the region close to Mainland China. Two regions demonstrated relatively large velocity. One was close to the Taiwan coast. The other one was near the bottom east of Wu-Chiu Island. West of Wu-Chiu Island, a weak southwestward current was observed.

\section{Discussion and summary}

Generally speaking, the Kuroshio around Taiwan demonstrated moderate temporal variation, but complicated spatial distribution, especially around the Luzon Strait and northeast of Taiwan. The spatial complication was caused primarily by local topography. Ignoring variations caused by westward propagating eddies, the observed current velocity at I-Lan Ridge (Johns et al., 2001) did not vary with time significantly. The Kuroshio showed small temporal fluctuations also confirmed by the moored current velocity in Luzon Strait. This result implies that the Kuroshio around Taiwan might be stable in time. In contrast to the velocity, the Kuroshio migrated intra-seasonally and seasonally. The seasonal migration was especially obvious north of I-Lan Ridge. Such seasonal migration caused large temporal variations in the moored current velocity at shelf break northeast of Taiwan. 
Because of insufficient data, cross-section of seasonal current distributions was not presented. Rough seas frequently prohibited the activities of research vessels in winter. The Sb-ADCP data were less in the northeasterly than the southwesterly monsoon seasons. Inevitably, the composite current velocity was biased favoring the current-velocity distribution during the southwesterly monsoon season. Nevertheless, the moored current velocity showed that the current around Taiwan had little seasonal variation, especially in the deep-water region. In the shallow regions, such as Taiwan Strait, the composite current-velocity vectors showed those similar tendencies as the mean moored current-velocity vectors obtained during mainly the northeasterly monsoon. Therefore, the bias could not change the distribution of composite current significantly.

The qualitative, but not quantitative, validity of composite current was supported by twelve sets of moored currents. The results showed that the Kuroshio intruded into the South China Sea through the northern-central Luzon Strait regardless of season, but its incident angle could vary with season. The Kuroshio with double velocity cores was seen east of southern Taiwan, but the two cores gradually combined into one before the I-Lan Ridge, which deflected the Kuroshio. The Kuroshio branched as it collided with the zonalrunning shelf break northeast of Taiwan. The main stream of the Kuroshio flowed along the shelf break to the east and a part of the Kuroshio intruded into the shelf. A submerged countercurrent between the Kuroshio and the shelf break was consistently observed. The seasonal migration of the Kuroshio influenced the countercurrent and the current northeast of Taiwan.

The intruding Kuroshio water in the South China Sea interacted with the South China Sea current. A clockwise flow pattern was seen southwest of Taiwan. Most of the water in this clockwise current returned to the Kuroshio at the tip of southern Taiwan. The rest of the water flowed into the Taiwan Strait through the Peng$\mathrm{Hu}$ Channel and is an important resource for current in the Taiwan Strait. The current in the Taiwan Strait primarily flowed to the north. A countercurrent was faintly visible along the coast of Mainland China. The Taiwan Strait outflow interacted with the intruding Kuroshio north of Taiwan. Only a small portion of outflow entered the Kuroshio along the northern coast of Taiwan. The rest of outflow continued north.

\section{Acknowledgements}

The research was supported by NSC of ROC under grants NSC 89-2611-M-002-031-OP2 for T. Y. Tang, NSC 90-2611-M-012-001-OP2 for Y. J. Yang, and NSC 89-2611-M-002-023-OP2 for W.S. Chuang. We express our thanks to the ODB/ NCOR for the historical Sb-ADCP and bathymetry data. The assistance of the captains and crews of the R/Vs ORI, II, and III are also greatly appreciated. The plotting software of curved velocity vectors was kindly provided by Dr. D. S. Ko at Naval Research Laboratory, Stennis Space Center (NRLSSC).

\section{References}

Chu, T.-Y., 1961. On ocean currents in East China Sea and the Variability of Taiwan. Meteorological Bulletin 4, 7-17 (in Chinese with English abstract).

Chu, T.-Y., 1976. Study of the kuroshio current between the Taiwan and Ishigakijima. Acta Oceanographica Taiwanica 13, 140-153.

Chuang, W.-S., 1986. A note on the driving mechanisms of current in the Taiwan Strait. Journal of Oceanography Society Japan 42, 355-361.

Chuang, W.-S., Liang, W.-D., 1994. Seasonal variability of intrusion of the Kuroshio water across the continental shelf northeast of Taiwan. Journal of Oceanography 50, 531-542.

Chuang, W.-S., Wu, C.-K., 1991. Slope-current fluctuation northeast of Taiwan, winter 1990. Journal of Oceanography Society Japan 47, 185-193.

Chuang, W.-S., Li, H.-W., Tang, T.Y., Wu, C.-K., 1993. Observation of the countercurrent on the inshore side of the Kuroshio northeast of Taiwan. Journal of Oceanography 49, 581-592.

Johns, W.E., Lee, T.N., Zhang, D., Zantopp, R., Liu, C.-T., Yang, Y., 2001. The Kuroshio east of Taiwan: moored transport observations from the WOCE PCM-1 array. Journal of Physical Oceanography 31, 1031-1053.

Li, L., Wu, B., 1989. A Kuroshio loop in South China Sea? On circulation of the northeaster South China Sea. Journal of Oceanography in Taiwan Strait 8, 89-95. 
Liu, C.-T., 1983. As the Kuroshio turns: (I) Characteristics of the current. Acta Oceanographica Taiwanica 14, $88-95$.

Metzger, E.J., Hurlburt, H.E., 2001. The nondeterministic nature of Kuroshio penetration and eddy shedding in the South China Sea. Journal of Physical Oceanography 31, $1712-1732$.

Nitani, H., 1972. Beginning of the Kuroshio. In: Stommel, H., Yoshida, K. (Eds.), Kuroshio, its physical aspects. University of Tokyo Press, Tokyo, pp. 129-163.

Qu, T., Mitsudera, H., Yamagata, T., 2000. Instruction of the North Pacific waters into the South China Sea. Journal Geophysical Research 105, 6415-6424.

Shaw, P.-T., 1989. The instruction of water masses into the sea southwest of Taiwan. Journal Geophysical Research 94, 18213-18226.

Shaw, P.-T., Chao, S.-Y., 1994. Surface circulation in the South China Sea. Deep-Sea Research 41, 1663-1683.

Sun, X., 1987. Analysis of the surface path of the Kuroshio in the East China Sea. In: Sun, X. (Ed.), Essays of the Investigation of Kuroshio. Ocean Press, Beijing, pp. 1-14 (in Chinese with English Abstract).

Tang, T.Y., Yang, Y.J., 1993. Low frequency current variability on the shelf break northeast of Taiwan. Journal of Oceanography 49, 193-210.
Tang, T.Y., Ma, J.C., 1995. A note on the accuracy of shipboard ADCP on Ocean Researcher I. Acta Oceanographica Taiwanica 34, 71-81.

Tang, T.Y., Hsueh, Y., Yang, Y.J., Ma, J.C., 1999. Continental slope flow northeast of Taiwan. Journal of Physical Oceanography 29, 1353-1362.

Tang, T.Y., Tai, J.H., Yang, Y.J., 2000. The flow pattern north of Taiwan and migration of the Kuroshio. Continental Shelf Research 20, 349-371.

Wang, J., Chern, C.-S., 1988. On the Kuroshio branch in the Taiwan Strait during wintertime. Progress in Oceanography 21, 469-491.

Wang, J., Chern, C.-S., 1989. On cold water instructions in the eastern Taiwan Strait during the cold season. Acta Oceanographica Taiwanica 21, 469-491.

Wyrtki, K., 1961. Physical oceanography of the southeast Asia waters. Scripps Institute of Oceanography NAGA Report, Vol. 2, 195pp.

Yang, Y., Liu, C.-T., Hu, J.-H., Koga, M., 1999. Taiwan Current (Kuroshio) and impinging eddies. Journal of Oceanography 55, 609-617.

Zhang, D., Lee, T.N., Johns, W.E., Liu, C.-T., Zantopp, R., 2001. The Kuroshio east of Taiwan: Modes of variability and relationship to interior ocean mesoscale eddies. Journal of Physical Oceanography 31, 1054-1074. 